\title{
Three-dimensional multislice helical computed tomography in the diagnostics of vena azygos connection to the caudal vena cava in a dog - a case report
}

\section{Mensur Šehić'*, Ivana Kiš², Dražen Vnuk³, Dženita Hadžijunuzović Alagić4, Dino Stanin', and Hrvoje Capak ${ }^{1}$}

\author{
'Department of Radiology, Physical Therapy and Ultrasound Diagnostic, Faculty of Veterinary Medicine, \\ University of Zagreb, Zagreb, Croatia \\ ${ }^{2}$ Clinic for Internal Diseases, Faculty of Veterinary Medicine, University of Zagreb, Zagreb, Croatia \\ ${ }^{3}$ Clinic of Surgery, Orthopaedics and Ophthalmology, Faculty of Veterinary Medicine, University of Zagreb, \\ Zagreb, Croatia \\ ${ }^{4}$ Department of Radiology and Physical Therapy Veterinary Faculty, University of Sarajevo, Sarajevo, \\ Bosnia and Herzegovina
}

\begin{abstract}
ŠEHIĆ, M., I. KIŠ, D. VNUK, DŽ. HADŽIJUNUZOVIĆ ALAGIĆ, D. STANIN, H. CAPAK: Three-dimensional multislice helical computed tomography in the diagnostics of vena azygos connection to the caudal vena cava in a dog - a case report. Vet. arhiv 87, 631-639, 2017.
\end{abstract}

\section{ABSTRACT}

In a four-year old Australian Cattle Dog bitch, CT angiography of the communication of the azygos vein with the interrupted caudal vena cava, without portocaval shunting is described. The communication of the azygos vein with the discontinued caudal vena cava is usually an incidental finding which does not appear with portocaval shunting. CT angiography and 3D multiplanar reconstruction (MIP and VR) enable us to distinguish the processes regarding the direction and size of anomalies of the blood vessels. By means of imaging in two basic projections using the velocity ratio (VR) a significant enlargement and the communication of the caudal vena cava with a significantly enlarged azygos vein and its connection with the cranial vena cava is shown.

Key words: vena azygos, caudal vena cava, computed tomography, Australian Cattle Dog, CT angiography, 3D multiplanar reconstruction

\footnotetext{
*Corresponding author:

Mensur Šehić, DVM, Professor Emeritus, Department of Radiology, Physical Therapy and Ultrasound Diagnostic, Faculty of Veterinary Medicine, University of Zagreb, Heinzelova 55, 10000 Zagreb, Croatia, Phone: +385 16524 943; Mob. +385 99 6778 267; E-mail: smensur873@gmail.com
} 
M. Šehić et al.: Three-dimensional multislice helical computed tomography in the diagnostics of vena azygos connection to the caudal vena cava in a dog

\section{Introduction}

In mammals the VCC (caudal vena cava) is formed from a series of processes which are involved in its development, regression and anastomosis, and it consists of three pairs of embryonal blood vessels: the supracardinal, subcardinal and navel veins (BUTLER, 1927; SCHWARZ et al., 2009). The anomalies which affect the venous system are rare in domestic carnivores. Most of the published cases involve a portosystemic shunt (SUTER, 1976; REIHE, 1972; BERTOLINI et al., 2006), and persisting left cranial vena cava. The possibility of elongation of the azygos vein with the caudal vena cava has also been explored (MARTIN and GERRITY, 1980; McCLURE and CONSTANTINESCU, 1987). The deficit includes part of the caudal vena cava, between the kidney and the liver. The connection of the caudal vena cava with the azygos vein enables the flow of blood from the caudal vena cava towards the right atrium, through the azygos vein and the cranial vena cava (BARTHEZ et al., 1996; FISCHETTI and NOVAK, 2008). In aplasia of the caudal vena cava a connection may also appear between its cranial part and the azygos vein (SCHWARZ et al., 2009; HARDER, 2002). This anomaly was discovered by means of laparotomy. Hepatic veins are connected with the hepatic segment of the caudal vena cava towards the right atrium. Such and similar anomalies cannot be shown on native abdominal x-ray, while ultrasonography gives insufficient data on the continuity of the azygos vein with the caudal vena cava. The best way to diagnose a connection between the caudal vena cava and the azygos vein is angiography, by means of computer tomography (CT) and 3D reconstruction (BERTOLINI et al., 2014; BERNARDIN et al., 2013). A double VCC is a rare occurrence in small animals. In their report on this anomaly, BERTOLINI et al. (2014) state that it was primarily described as an accidental finding during imaging for other reasons, and it also appears along with other congenital anomalies.

Multiple CT layers are perhaps the best way to describe the modern development of spiral computer tomography. This notion is mainly based on simultaneous multislice imaging. This is the result of a multiple system of detectors and it is often called "Multidetector CT" (Multislice, MSCT). 3D imaging is a widely spread procedure in computer tomography because it uses a large quantity of digital data (ŠEHIĆ, 2007). 3D images can be obtained by a hardware approach using a special device, e.g. an electronic computer unit for display of the algorithm obtained for 3D imaging. These algorithms, or the technique of automatic imaging, transform transaxial CT data into simulated 3D images.

CT angiography is defined as CT imaging of blood vessels opacified with a contrast agent (ZWINGERBERGER and SCHWARZ, 2004; ŠEHIĆ, 2007). During the injection of the contrast agent, the entire target area of examination is scanned by spiral CT, and the imaging is done when the blood vessels are completely opacified, with the aim of 
M. Šehić et al.: Three-dimensional multislice helical computed tomography in the diagnostics of vena azygos connection to the caudal vena cava in a dog

showing the venous and arterial phase. CT angiography uses the principles of 3D imaging to display the blood vessel network by means of intravenously injected contrast agent.

\section{Materials and methods}

An Australian Cattle Dog bitch, four years old, was brought for internist examination at nine months old with anamnestic data that she had slipped in the mud and its rear legs had degun to jerk uncontrollably. This seizure lasted only a short time. After that, she was quiet for several months, but began to manifest similar signs of seizure again, which lasted only a few seconds. Before coming to the clinic she had staggered, hit a fence, collapsed on the ground and lay motionless. Then, she got up and showed normal motoric activity. Clinically, the bitch manifested signs of cramp with completely flexed legs. Other signs were normal. When walking, she sometimes staggered, especially on a muddy surface. Otherwise, she was cheerful and ate and drank normally. Her stool and urine were normal. Auscultation showed no pathological changes in the lungs or the heart. The abdomen was compressible and painless.

Radiology showed a sharply delineated homogeneous oval structure, c. $4.4 \mathrm{~cm}$ in diameter, in the mesentery. Its nature could not be determined by native x-ray. During ultrasonography examination, three anechoic structures were identified behind the right kidney. They were sharply delineated and located along the same long axis, with communication between them. The circulation and mixing of hypo- and anechoic content was visible inside them. The largest one was cyst-like, with $5.9 \times 4.57 \mathrm{~cm}$ diameter and corresponded to a vascular structure, probably to the caudal vena cava. Blood and biochemical findings were within physiological limits. After diagnostic laparotomy, which showed that the cystic structure belonged to the caudal vena cava, we refrained from further surgery.

Anaesthesia and CT angiography were performed. A catheter was inserted into the right saphenous vein, and further into the right iliac and caudal vena cava. The catheter could not go further cranially from the central part of the abdomen, where ultrasound showed a visible turning of the vein. With injection of the contrast agent (Iohexol, 180 $\mathrm{mgU} / \mathrm{mL}$ ), anastomosis became visible between the caudal vena cava and the azygos vein (Fig. 1a and b). Following CT angiography, multiplane reconstructions (MPR) were made, maximum intensity projections (MIP) and velocity ratio (VR). The analysis of the obtained results showed a continuity of the azygos vein and the caudal vena cava. The vascular anomaly did not show clinical signs. 
M. Šehić et al.: Three-dimensional multislice helical computed tomography in the diagnostics of vena azygos connection to the caudal vena cava in a dog

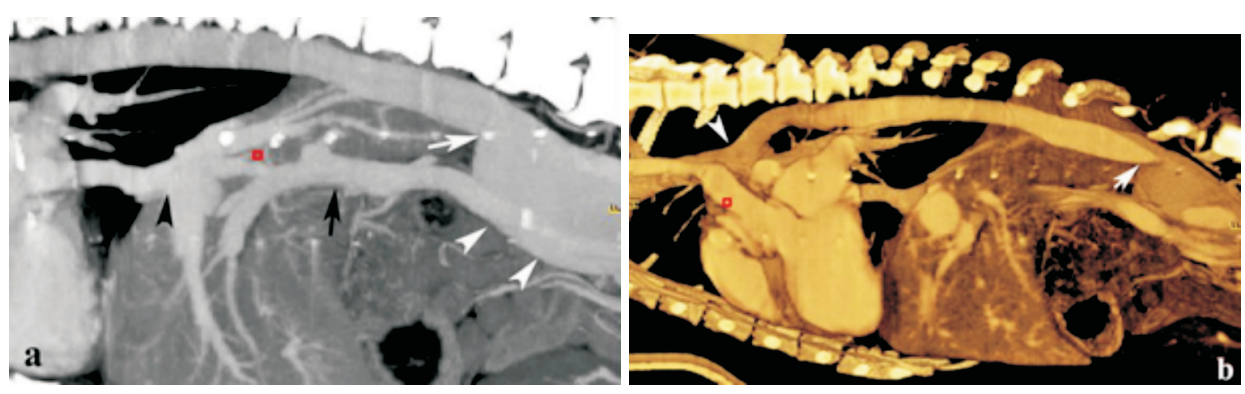

Fig. 1a and b. (a) Veins filled with a contrast agent were shown in maximum intensity projection (MIP). The white arrow shows the point of connection of the enlarged caudal vena cava and the dilated azygos vein. The tips of the white arrows show the location of the significantly enlarged caudal vena cava. The dark arrow shows the portal vein. The dark tip of the arrow is at the location of the caudal interruption of the caudal vena cava, and the point of branching of the hepatic vein. (b) In the VR reconstruction, the connection of the azygos vein and the enlarged part of the caudal vena cava is well emphasized (arrow). The tip of the arrow shows the point of inflow of the azygos vein into the cranial vena cava.

\section{Results}

The thorax and abdomen are displayed in multiple cross-sectional CT slices, at a slice width of $1 \mathrm{~mm}$ (Fig. 2a and b). After recording initial data, CT angiography was performed. The optimal time for display of the caudal vena cava and the portal vein was determined by manual application of an iodine-based contrast agent (Iohexol, 180 $\mathrm{mgU} / \mathrm{mL}$ ). Two minutes after the complete injection of the contrast agent, the portal vein and the hepatic vein were shown. Immediately after that, the arterial phase appeared. $3 \mathrm{D}$ reconstruction was performed from a large number of cross-sectional images of the abdomen and thorax, and the images are mostly displayed with the velocity ratio (VR).

The prehepatic caudal vena cava is not recognizable. The posthepatic caudal vena cava is formed according to the influx of hepatic veins which spread cranially through the caval hiatus (Fig. 4). The portal vein enters normally into the liver, without a systemic venous communication. The azygos vein and the caudal vena cava connect with the cranial vena cava and the right atrium as expected.

Caudally from the enlarged part, the caudal vena cava is twice as wide as the abdominal aorta (Picture 5). At the site of the branching of both blood vessels, the iliac veins are also twice as wide as the width of the iliac arteries.

The diagnosis was made on the basis of the imaging techniques. The finding that the azygos vein is a continuation of the caudal vena cava without a portosystemic shunt was incidental and occurred during the examination of the abdomen. After one year the dog no longer manifested pathological behaviour. 
M. Šehić et al.: Three-dimensional multislice helical computed tomography in the diagnostics of vena azygos connection to the caudal vena cava in a dog
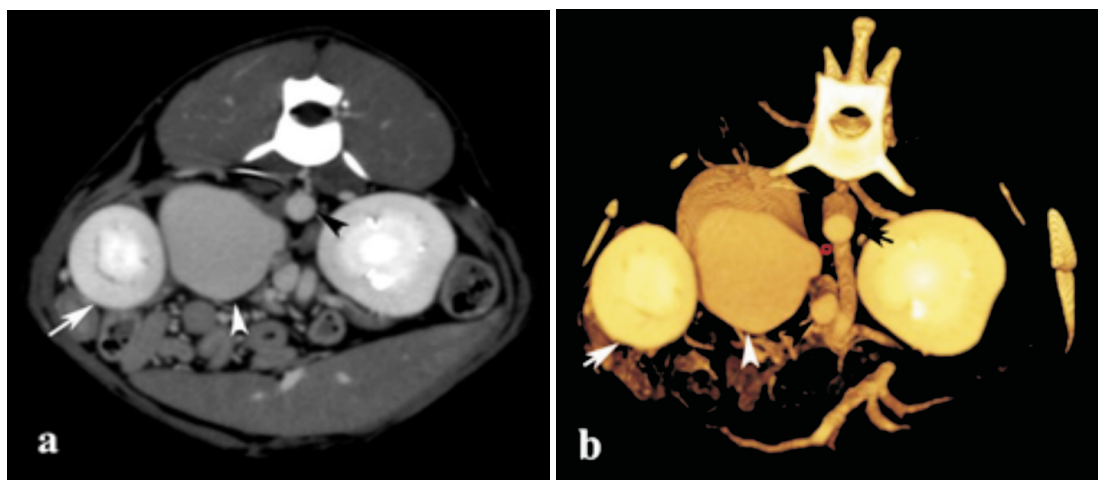

Fig. 2 a and b. (a) A cross-sectional CT image was recorded in the kidney area, where, alongside the right kidney (white arrow), the enlargement of the cranial end of the caudal segment of the caudal vena cava is displayed (tip of the white arrow). The dark tip of the arrow shows the aorta.

(b) With the velocity ratio (VR) in cross-section a similar slice to the one on picture (a) was obtained (the light arrow is the right kidney, the tip of the white arrow is the enlargement of the caudal vena cava, and the dark arrow shows the cross-section of the aorta).
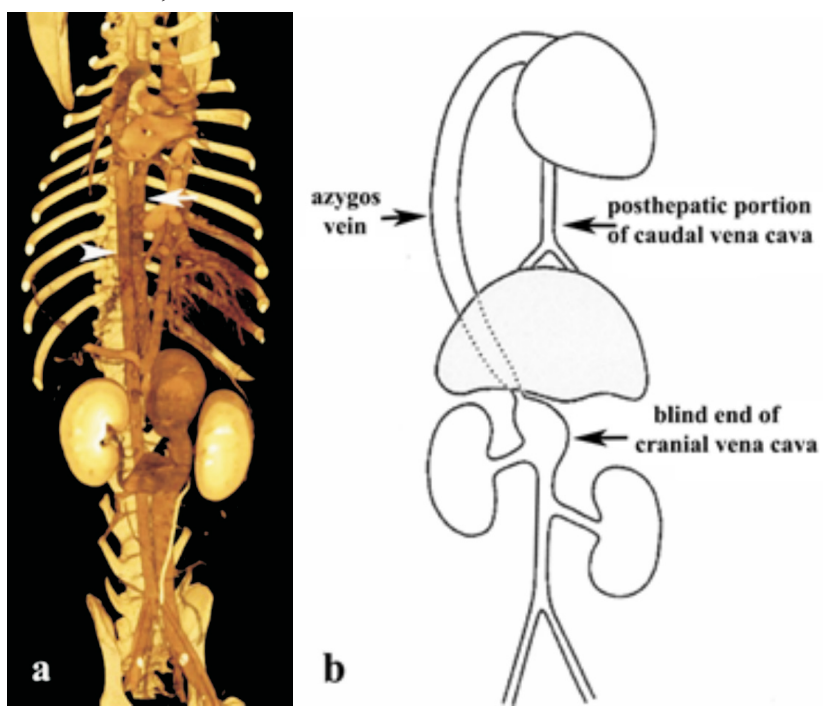

Fig. 3a and 3b. (a) Reconstruction of the image by velocity ratio (VR) shows a parallel spreading of the aorta (tip of the arrow) and the azygos vein (arrow). The width of these blood vessels is approximately equal. Distally, in the further anatomical course, the connection of the enlarged part of the VCC and azygos vein. Distally from the enlarged right kidney vein, the significantly enlarged caudal vena cava and the iliac veins continue and are twice as wide as the abdominal aorta and its iliac branches. (b) Schematic drawing of part of image (a). 
M. Šehić et al.: Three-dimensional multislice helical computed tomography in the diagnostics of vena azygos connection to the caudal vena cava in a dog

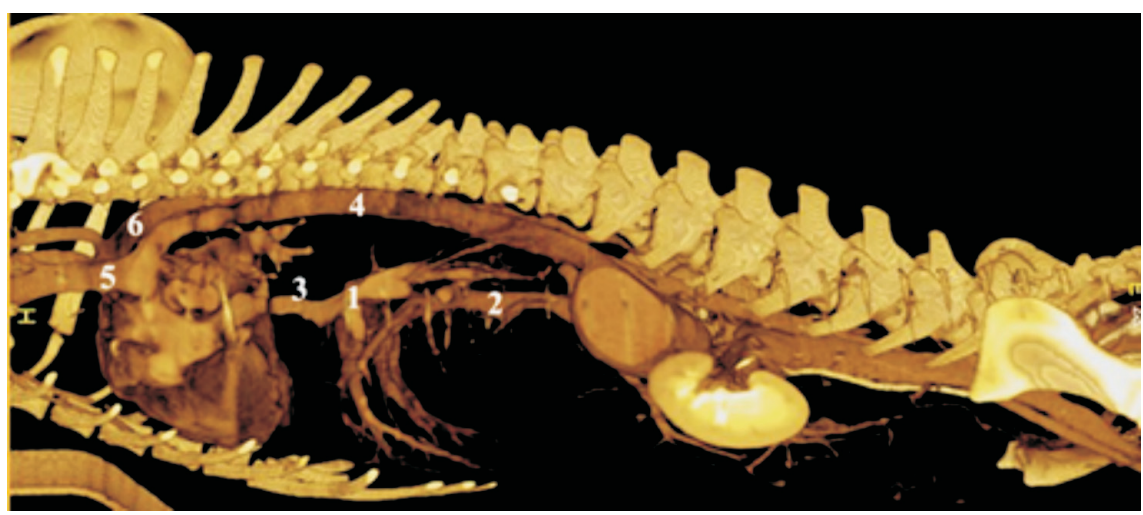

Fig. 4. Sagittal image of the thorax and abdomen by velocity ratio (VR), emphasizing the following veins: 1 . Vena hepatica; 2 . Vena portae; 3 . Posthepatic caudal vena cava (VCC); 4. Vena azygos; 5. Cranial vena cava (VCCr); 6. Aortic arch.

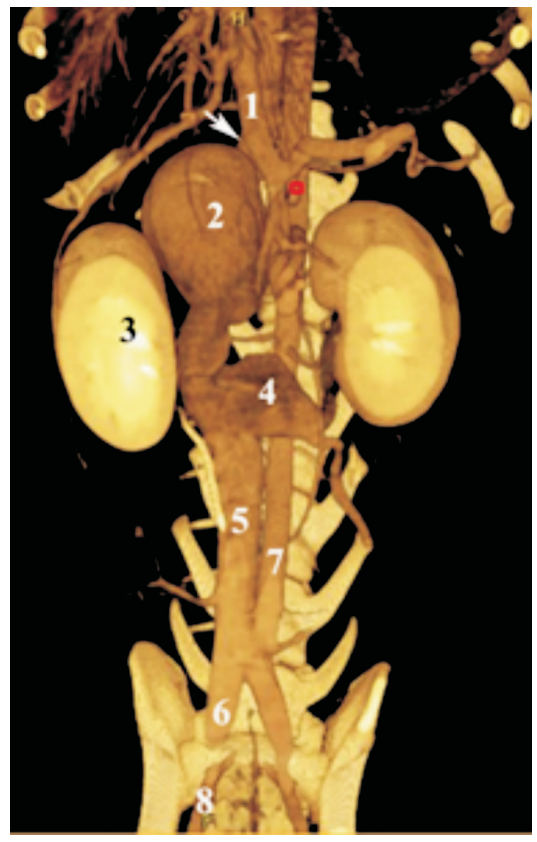

Fig. 5. In dorsal projection we observe the blood vessels by means of velocity ratio (VR): 1. Vena portae; 2 . The enlarged part of the caudal vena cava at the connecting point with the azygos vein (arrow); Right kidney; 4. Enlarged left renal vein; 5. The caudal vena cava, nearly twice as wide as the aorta; 6 . The enlarged iliac external vein; 7. Aorta; 8 . A. iliaca externa. 
M. Šehić et al.: Three-dimensional multislice helical computed tomography in the diagnostics of vena azygos connection to the caudal vena cava in a dog

\section{Discussion}

The frequency of anomalies of the caudal vena cava in healthy dogs is around $1 \%$ (BUCHANAN, 1992). In man and in dog congenital malformations of the caudal vena cava are usually incidental, i.e. they are found during diagnostic procedures not directed at this problem. The anomalies relate to a portosystemic shunt, connection of the caudal vena cava with the azygos vein, situs inversus and double caudal vena cava (HUNT et al., 1998; LABORDA et al., 1996; BARTHEZ et al., 1996; BERTOLINI et al., 2014). The embryonic foundation for the connection of the azygos vein with the caudal vena cava from a discontinuous prehepatic caudal vena cava has been described in detail (BUCHANAN, 1992; HUNT et al., 1998; BARTHEZ et al., 1996; NODEN and de LAHUNTA, 1985).

The caudal vena cava develops from the main veins caudally from the liver and navel veins, within and cranially towards the liver. The azygos vein develops from the supracardinal vein. During normal development, there is a continuum from the embryonal caudal vena cava and the azygos vein. This connection is severed with the regression of the supracardinal vein. However, if the supracardinal vein (prehepatic vena cava) fails to develop, to provide a connection with the navel veins (hepatic and posthepatic vena cava), the supracardinal vein will not regress, allowing the blood from the caudal part of the body to enter the heart via the azygos vein. As the posthepatic vena cava develops from the navel veins, a normal caudal vena cava will develop from the severed hepatic veins, cranially towards the liver. The more frequent use of CT in veterinary medicine may lead to better recognition of the connection of the azygos vein with the caudal vena cava in dogs examined for portosystemic shunt, or other unrelated abdominal conditions.

The optimal time for imaging the portal vein is 90 seconds or more after the injection of the contrast agent, which suffices for auxiliary staff to leave the room before the scan itself (FRANK et al., 2003). HARDER et al. (2002) used magnetic resonance imaging (MRI) to display the blind ending of the caudal vena cava at the level of the right kidney with dilated blood vessels of this region. As in our case, the dilatation of the stub of the caudal vena cava was determined. Segment aplasia of the caudal vena cava, with secondary thrombus was diagnosed. Two days later laparotomy revealed the blind ending of the caudal vena cava at the level of the right kidney, where the dilated end of the vein was 4 $\times 7 \mathrm{~cm}$.

In our case, we diagnosed, by means of spiral $\mathrm{CT}$ angiography and 3D reconstruction the continuity of the azygos vein with the caudal vena cava. The reconstruction of the image by velocity ratio (VR) emphasized the parallel stretching of the aorta and the azygos vein. The width of these blood vessels was almost equal. Distally, in the further course we found the connection of the enlarged part of the VCC $(5.9 \times 4.57 \mathrm{~cm})$ with the azygos vein. Distally from the enlarged right kidney vein, the continuation was seen of the significantly enlarged caudal vena cava and the iliac veins, which were twice as wide 
M. Šehić et al.: Three-dimensional multislice helical computed tomography in the diagnostics of vena azygos connection to the caudal vena cava in a dog

as the abdominal aorta and its iliac branches. The continuity of the azygos vein and the caudal vena cava is unrelated to the clinical signs.

In the available literature we failed to find any such impeccable image by CT angiography of a connection of the caudal vena cava with the azygos vein, ending in the cranial vena cava. Of all multiplanar reconstructions the best was provided by the velocity ratio (VR), which, with its plastic display, showed detailed recognition of all the changes to the above mentioned blood vessels.

\section{References}

BARTHEZ, P. Y., L. M. SIEMENS, P. D. KOBLIK (1996): Azygos continuation of the caudal vena cava in a dog: radiographic and ultrasonographic diagnosis. Vet. Radiol. Ultrasound 37, 354-356.

BERNARDIN, F., A-L. FREULON, R. RIGAUD, T. RIBAS, L. JAILLARDON, C. CHERVIER, T. CHUZEL, E. VIGUIER, R. PARIAUT, I. BUBLOT (2013): Shunting between the CVC and both the azygos vein and thoracic duct in a dog with CTD. J. Am. Anim. Hospital Assoc. 49, 128-134.

BERTOLINI, G., E. C. ROLLA, A. ZOTTI, M. CALDIN (2006): Three-dimensional multislice helical computed tomography techniques for canine extrahepatic portosystemic shunt assessment. Vet. Radiol. Ultrasound 47, 439-443.

BERTOLINI, G., A. DIANA, M. CIPONE, M. DRIGO, M. CALDIN (2014): Multidetector row computed tomography and ultrasound sharacteristics of caudal vena cava duplication in dogs. Vet. Radiol. Ultrasound 55, 521-530.

BUCHANAN, J. W. (1992): Causes and prevalence of cardiovascular desease. In: Current Veterinary Therapy. (Kirk R. W., J. D. Bonagura, Eds.). XI. Philadelphia: Saunders, pp. 647-652.

BUTLER, E. G. (1927): The relative role played by embrionic veins in the development of the mammalian vena cava posterior. Am. J. Anat. 39, 267-353.

FISCHETTI, A. J., J. KOVAK (2008): Imaging diagnosis: azygous continuation of the caudal vena cava with and without portocaval shunting. Vet. Radiol. Ultrasound, 49, 573-576.

FRANK, P., M. MAHAFFEY, C. EGGER, K. K. CORNELL (2003): Helical computed tomographic portography in ten normal dogs and ten dogs with portosystemic shunt. Vet. Radiol. Ultrasound 44, 392-400.

HARDER, M. A., D. FOWLER, J. W. PHARR, K. A. TRYON, C. SHMON (2002): Segmental aplasia of the caudal vena cava in a dog. Can. Vet. J. 43, 365-368.

HUNT, G. B., C. R. BELLENGER, R. BORG, K. R. YOUMANS, P. L. C. TISDALL, R. MALIK (1998): Congenital interruption of the portal vein and caudal vena cava in dogs: portosystemic shunt assessment. Vet. Radiol. Ultrasound 47, 439-443.

LABORDA, J., M. GIMENO, L. DOMINGUEZ, J. GIL (1996): Anomalous caudal vena cava in the dog. Vet. Rec. 138, 20-21. 
M. Šehić et al.: Three-dimensional multislice helical computed tomography in the diagnostics of vena azygos connection to the caudal vena cava in a dog

MARTIN, J. E., L. W. GERRITY (1980): Azygos continuatation of the caudal vena cava in a dog. Southwestern Vet. 33, 155-157.

McCLURE, R. C., G. M. CONSTANTINESCU (1987): An uncommon right azygous vein and caudal vena cava in the dog. Anat. Histol. Embryol. 16, 84.

NODEN, D. M., A. de LAHUNTA (eds) (1985): The Embriology of Domestic Animals: Developmental Mechanisms and Malformations. Baltimore: Williams and Wilkins, 257-269

REIHE, C. (1972): Anomaly of the vena cava caudalis in a dog. Zbl. Vet. Med. A. Anatomie, Histologie, Embryologie. 1, 149-152.

SCHWARZ, T., F. ROSSI, J. D. WRAY, B. ÅBLAD, M. W. BEAL, J. KINNS, G. S. SEILER, R. DENNIS, J. F. McCONNELL, M. COSTELLO (2009): Computed tomographic and magnetic resonance imaging features of canine segmental caudal vena cava aplasia. J.S.A.P. 50, 341349.

SUTER, P. F. (1976): Portal vein anomalies in the dog: their angiographic diagnosis. J. Am. Radiol. Soc. $17,106-112$.

ŠEHIĆ, M. (2007): Kompjutorizirana tomografija psa i mačke. Veterinarski fakultet, Zagreb.

ZWINGENBERGER, A. L., T. SCHWARZ (2004): Dual-phase CT angiography of the normal canine portal and hepatic vasculature. Vet. Radiol. Ultrasound 45, 117-124.

Received: 23 June 2016

Accepted: 12 May 2017

\begin{abstract}
ŠEHIĆ, M., I. KIŠ, D. VNUK, DŽ. HADŽIJUNUZOVIĆ ALAGIĆ, D. STANIN, H. CAPAK: Trodimenzionalna višeslojna spiralna kompjutorizirana tomografija u dijagnostici povezanosti vene azigos s kaudalnom šupljom venom u psa - prikaz slučaja. Vet. arhiv 87, 631-639, 2017.

\section{SAŽETAK}

U članku je u kuje australskog govedarskog psa, u dobi od četiri godine, opisana CT angiografija komunikacije vene azigos s prekinutom kaudalnom venom kavom bez portokavalnoga šanta. Veza vene azigos s diskontinuiranom kaudalnom venom kavom obično je slučajan nalaz koji se ne pojavljuje s portokavalnim šantom. CT angiografija i 3D multiplanarna rekonstrukcija (MIP i VR) omogućavaju da se razluče prava zbivanja u smjeru i veličini anomalije krvnih žila. Slikovno, u dvije osnovne projekcije iscrtavanjem volumena (VR) prikazano je znatno proširenje i komunikacija kaudalne vene kave sa znatno proširenom venom azigos i njenim spojem s kranijalnom venom kavom.
\end{abstract}

Ključne riječi: pas, vena azigos, kompjutorizirana tomografija 
